\title{
Found at Old Age and Continuously Growing WHO Grade II Fourth Ventricle Ependymoma: A Case Report
}

\author{
Moowan Park ${ }^{1}$ Eun Kyeong Hong'2 , Sang Hyen Lee ${ }^{3}$, Ho-Shin Gwak ${ }^{4}$ \\ 'Department of Neurosurgery, Seoul National University College of Medicine, Seoul, Korea \\ Departments of ${ }^{2}$ Pathology, ${ }^{3}$ Radiology, ${ }^{4}$ Cancer Control, Graduate School of Cancer Science and Policy, National Cancer Center, Goyang, Korea
}

\author{
Received January 13, 2019 \\ Revised April 16, 2019 \\ Accepted June 11, 2019 \\ Correspondence \\ Ho-Shin Gwak \\ Department of Cancer Control, \\ Graduate School of Cancer Science \\ and Policy, National Cancer Center, \\ 323 Ilsan-ro, llsandong-gu, \\ Goyang 10408, Korea \\ Tel: +82-31-920-1666 \\ Fax: +82-31-920-2798 \\ E-mail: nsghs@ncc.re.kr
}

\begin{abstract}
A 74-year-old woman presented with a month-long nausea and vomiting, then she could not take a meal. She had found an asymptomatic 4th ventricular mass 6 year ago as a preoperative work-up for ovarian cancer. And during the yearly follow-up, the mass had grown continuously over 6 years, and caused symptoms in the seventh year. MRI revealed a large ovoid extra-axial mass in the fourth ventricle compressing adjacent medulla and cerebellum. Surgery achieved near total resection since the tumor tightly adhered to the brain stem of 4 th ventricle floor. The histological diagnosis was ependymoma (WHO grade II). She transferred rehabilitation facility for mild gait disturbance, hoarseness and swallowing difficulty. Fourth ventricle ependymoma in the elderly is extremely rare and the growth rate has not been reported. Here, we present a rare care of 4 th ventricle ependymoma found asymptomatic at elderly but continuously grow to cause local pressure symptoms.
\end{abstract}

Key Words Ependymoma; Grade II; Fourth ventricle; Elderly.

\section{INTRODUCTION}

Ependymoma is rare central nervous system tumor arising from ependymal cells lining the central canal of the spinal cord and ventricle of brain. They may occur supratentorial and posterior fossa, and spinal canal. As intracranial ependymoma is mainly a tumor of children, it makes up a $2 \%$ of adult intracranial tumors and $10 \%$ of the child ones [1]. Preferentially ependymoma of children is located at posterior fossa, whereas in adult, the tendency was less intensive and ependymoma is found often at supratentorial location [2]. Thus, posterior fossa ependymoma is extremely rare intracranial tumor in adults, especially in the elderly, and even up to one-third of pathologic diagnosis was mistaken to other tumors [1]. Histological grade and the extent of surgical resection were known to be significant for patients' prognosis $[1,3,4]$. High-grade ependymoma prevailed among pediatric patients, and supratentorial location. Although infratentorial ependymoma in adults was

This is an Open Access article distributed under the terms of the Creative Commons Attribution Non-Commercial License (https://creativecommons.org/licenses/by-nc/4.0) which permits unrestricted non-commercial use, distribution, and reproduction in any medium, provided the original work is properly cited.

Copyright $\odot 2019$ The Korean Brain Tumor Society, The Korean Society for NeuroOncology, and The Korean Society for Pediatric Neuro-Oncology known to be preferentially low grade ( $83 \%$ of WHO grade II), there is no consensus of treatment especially those found incidentally, especially in elderly patient.

\section{CASE REPORT}

A 68-year-old woman diagnosed with ovarian cancer referred to neurosurgical department from gynecologic department for abnormal finding of brain MRI, which was performed as a check-up before radical surgery of ovarian cancer in 2012. She had a past medical history of surgical clipping of ruptured anterior communicating artery aneurysm with subarachnoid hemorrhage, and subsequent ventriculo-peritoneal shunt due to post hemorrhagic hydrocephalus in 2005.

The preoperative T2-weighted MRI showed a $9 \times 5 \mathrm{~mm}$ sized, well delineated extra-axial ventricle mass on the 4 th ventricle floor, which was found retrospectively on the outside MRI in 2006 as $4 \mathrm{~mm}$ sized, 4 th ventricle mass (Fig. 1A, B). It appeared isointense on T1-weighted imaging showed fuzzy enhancement after gadolinium enhancement (Fig. 1C, D). As the mass was asymptomatic, the patient refused to receive exploratory operation and have taken regular follow-up MRI 

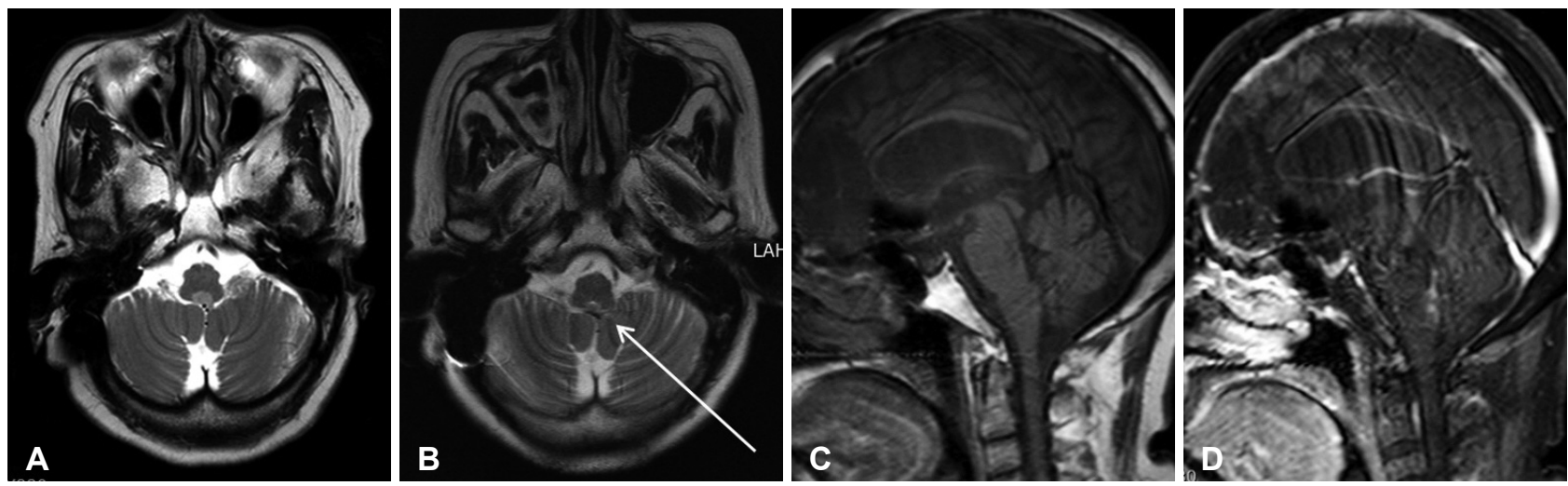

Fig. 1. Initial MRI at the time of diagnosis and retrospectively traced mass at 6 years ago MRI. A: Brain MRI revealed slightly high signal on T2-axial well-delinated ovoid mass in the 4th ventricle floor. B: The mass (arrow) was retrospectively found on MRI taken after aneurysmal clipping and ventriculo-peritoneal shunt 6 years ago. C: T1-sagittal MRI revealed, iso-signal intensity, and D: fuzzy enhancing mass after gadolinium enhancement.
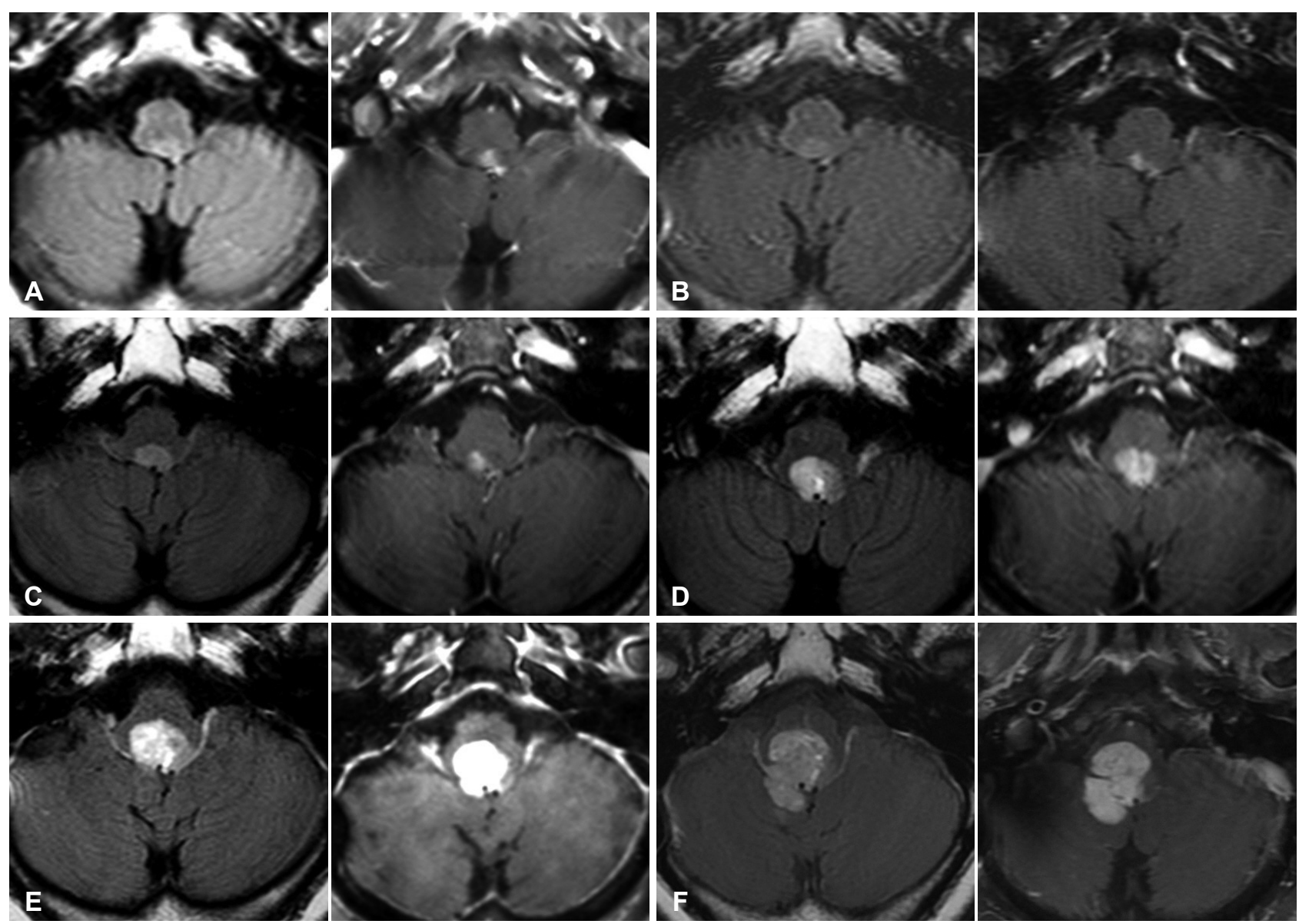

Fig. 2. Serial yearly follow up MRIs from 2013 to 2017 (A-F) reveal continuous growing 4th ventricle tumor on T2 (left of each) and T1 gadolinium enhanced image (right of each). The largest tumor diameter increased from $9 \mathrm{~mm}$ to $30 \mathrm{~mm}$ in 6 years but she remained asymptomatic up to 6 th year.

and clinical check-up once a year, instead. The size of the tumor had increased each follow-up, but she had remained asymptomatic up to 6th year (Fig. 2). In 6th year follow-up, we recommended surgical excisional biopsy in 2017 for the possibility of malignant brain tumor, as the maximum diameter of the tumor increasing from $9 \mathrm{~mm}$ to $30 \mathrm{~mm}$ relatively rapidly, and MR spectroscopy with perfusion image showed relatively elevated choline peak to N-acetylaspartate (NAA) peak, which was compatible with low to intermediate degree of malignancy. But her and her family refused to receive surgery. 

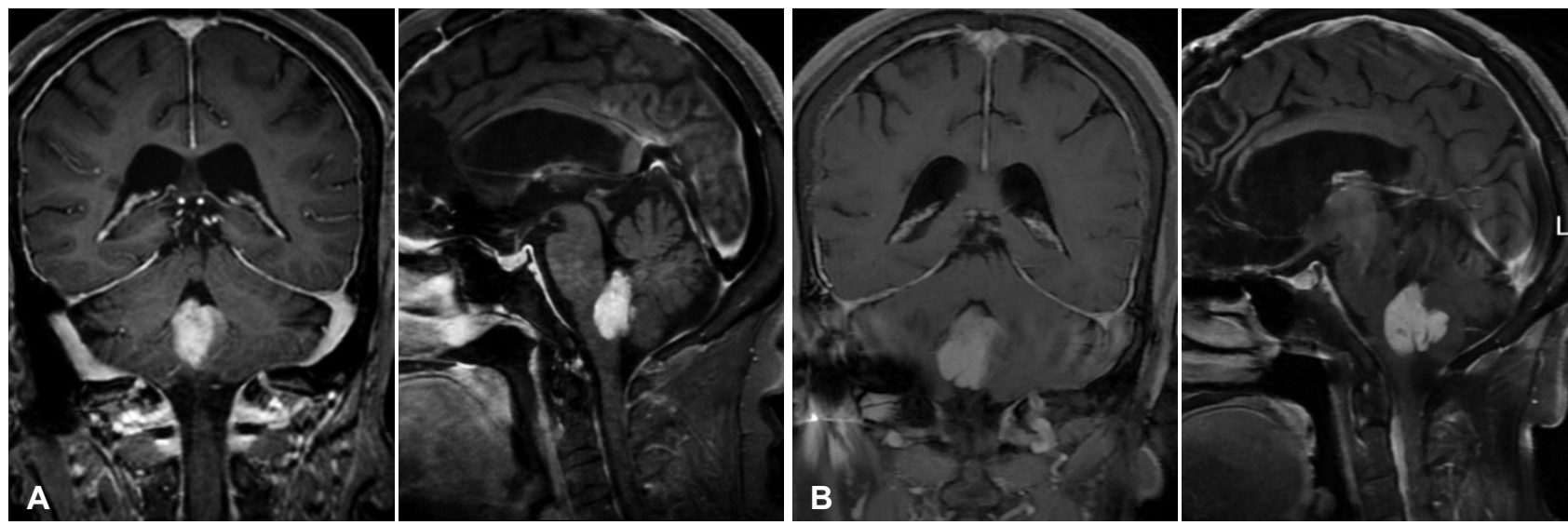

Fig. 3. Comparison of mass size on T1 gadolinium enhanced MR images between (A) the last year of patient being asymptomatic and (B) the 7 th year of patient developing intolerable nausea and vomiting at the age of 74 years-old.
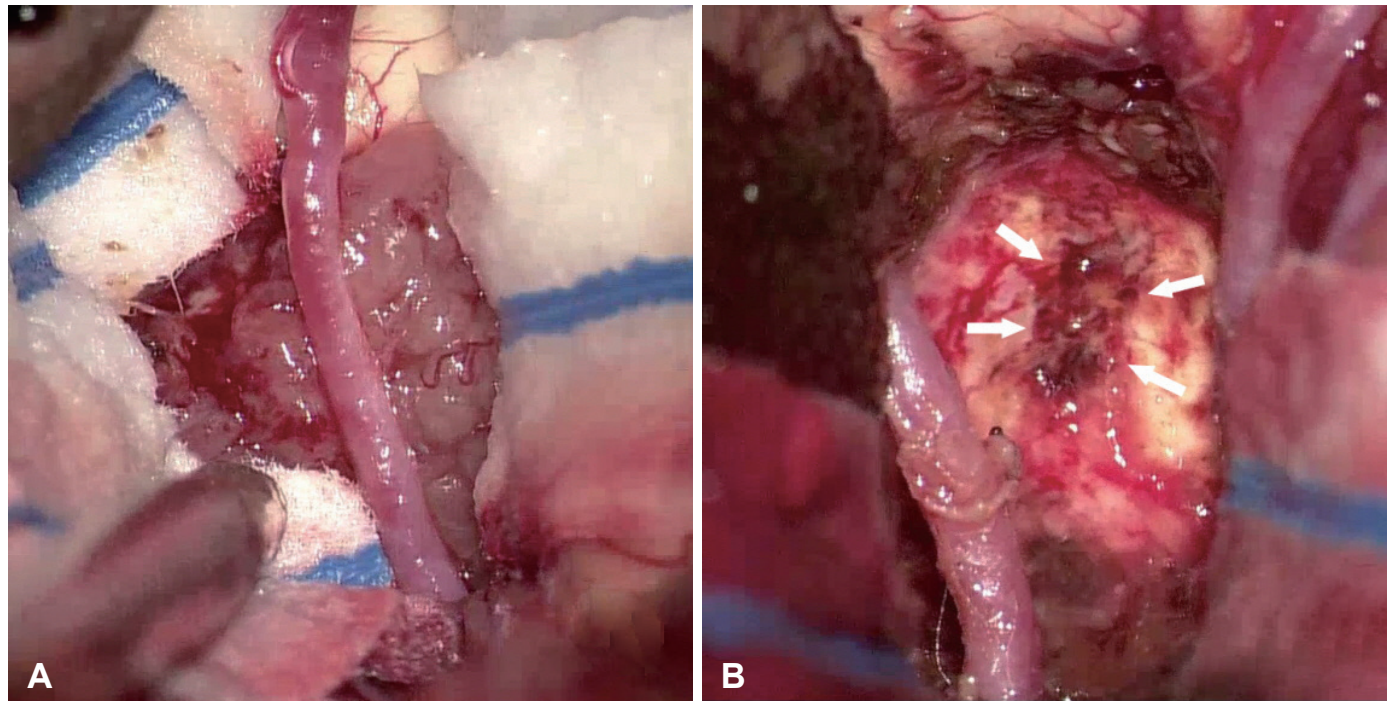

Fig. 4. Midline suboccipital craniotomy were used for resection of 4th ventricle tumor (A). The tumor was exposed between cerebellar tonsils. It was fragile and colored grey to purple (B). Using telovelar approach, we could easily dissect tumor from the cerebellum and the roof of 4th ventricle. We leaved small seam of tumor (arrows) adhered to dorsal lip of 4th ventricle, and near total resection of the tumor was achieved.

One year later, she vomited every day after meal and lost $5 \%$ of her weight. MRI follow-up showed the mass was extending through Foramen Magendie and compressing adjacent medulla and cerebellum (Fig. 3). The mass was enhanced with gadolinium and reached approximately $2.3 \times 2.5$ $\times 2.8 \mathrm{~cm}$ in diameter. The patient decided to receive operation to relief symptoms at 7 th year follow-up of 74 years-old.

We performed surgery via midline suboccipital craniotomy with electromyogram-sensing endotracheal tube for monitoring of lower cranial nerve. The tumor was exposed between cerebellar tonsils. It was fragile and colored grey to purple. The tumor was easily dissected from the cerebellum and the roof of 4th ventricle but, sit was tightly attached to the lower lip of 4th ventricle floor. Thus, we leaved small seam of tumor adhered to dorsal lip of 4th ventricle, and near total resection of the tumor was achieved (Fig. 4).
Histological examination showed relatively cellular tumor composed of small round cells arranged around blood vessels with intervening anucleate zones, forming perivascular pseudorosettes (Fig. 5A). In close up view, tumor cell processes converge on the blood vessels creating fibrillar zone of pseudo-rosettes (Fig. 5B). True ependymal rosettes having luminal spaces are also noted (Fig. 5C). On immunohistochemistry, dot-like perinuclear immunopositivity on epithelial membrane antigen stain was characteristic of ependymal cells (Fig. 5D). Ki-67 was positive for $3 \%$ of nuclei. The diagnosis was ependymoma (WHO grade II).

Postoperatively, she had hoarseness due to right vocal cord palsy, dysarthria, dysphagia, left side dysmetria, and aspiration tendency. So, she had to lean on Levin tube feeding, but rapidly recovered in 2 weeks and oral intake became possible with thickener. Postoperative MRI revealed total excision of 

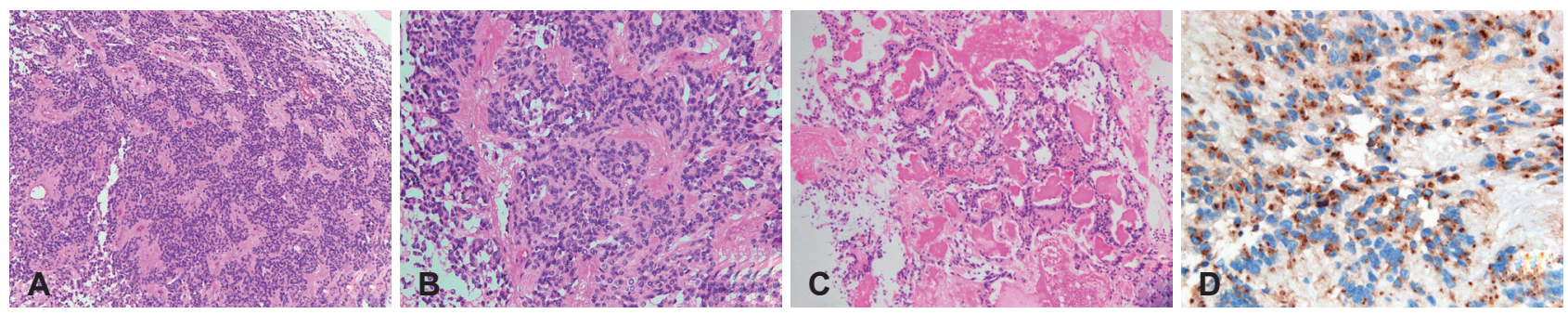

Fig. 5. Pathologic feature of ependymoma. A: This celluilar tumor is composed of small round cells. The tumor cells are arranged around blood vessels with intervening anucleate zones, forming perivascular pseudorosettes. $(\mathrm{H}-\mathrm{E}, \times 100)$. B: In close up view, tumor cell processes converge on the blood vessels creating fibrillar zone of pseudorosettes $(\mathrm{H}-\mathrm{E}, \times 200)$. C: True ependymal rosettes having luminal spaces are also noted $(\mathrm{H}-\mathrm{E}, \times 100)$. D: Dot-like perinuclear immunopositivity on EMA stain is characteristic. It indicates intracellular lumen of ependymal tumor cells $(E M A, \times 100)$. $\mathrm{H}-\mathrm{E}$, hematoxylin and eosin; EMA, epithelial membrane antigen.
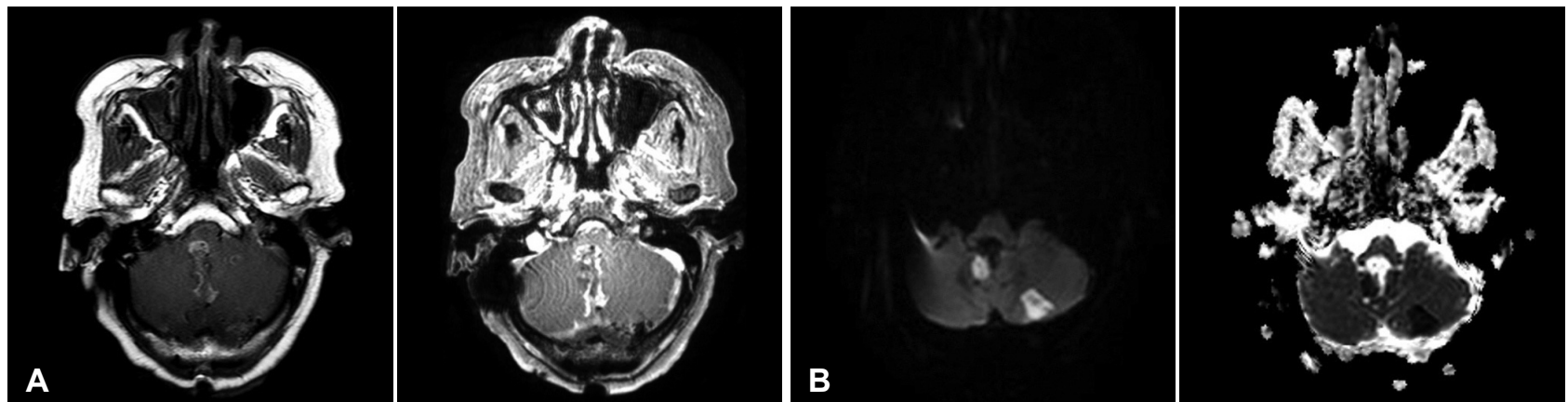

Fig. 6. Postoperative MRI revealed total excision of enhancing mass with linear enhancement of surgical tract (A). The region demonstrates abnormally diffusion restricted and low apparent diffusion coefficient values explain transient postoperative neurological deficit of the patient (B).

enhancing mass with linear enhancement of surgical tract (Fig. 6). We examined spine MRI for the possibility of drop metastasis of spine, but spinal cord surface and leptomeninges were clear of tumor cells. The intra-operative CSF cytology also showed no involvement of tumor. She received intensive rehabilitation for ataxia and postural instability, and laryngoplasty for hoarseness. She was transferred to rehabilitation facility at postoperative 3 weeks. At 3 months followup, she walked independently and ate normal diet.

\section{DISCUSSION}

Ependymal tumors are varied by histopathological grade, location, and genomics. The anatomical location is divided in the three part of the CNS system: spine, posterior fossa, and supratentorial and there is a tendency of different location depending on age. In children, two-thirds of ependymoma occurs in posterior fossa. On the contrary, it usually occurs on supratentorium in adults [1]. WHO grades tends to have different ratio depending of the location. In infratentorial ependymomas, WHO grade II account for 83\% of patients and especially $89.2 \%$ in patients older than 55 years [3]. But patients with age over 55 just account for $34.9 \%$ of infratentorial ependymoma. In this patient, the tumor occurred at infratentorium and WHO grade II despite being age of 68 years. Among infratentorial ependy- mal tumor found at 55 years-old or more, about $28 \%$ of cases were WHO grade II. From the literature, Hayashi et al. [5] found 9 cases of ependymoma diagnosed older than 60 years including 4 cases of 4 th ventricle ependymoma (Table 1) [5]. Present case is the 5th case of 4th ventricle ependymoma diagnosed at age of 60 years and older, and only case that was found asymptomatic at first presentation. Among those 5 cases, 4 cases were revealed to be WHO grade II.

Due to adjacent critical structures, posterior fossa, especially fourth ventricle, ependymoma is closely associated with neurological sequelae: gait and motor deficits, speech/ swallowing deficits, and cranial nerve deficit. The present case was suffered from vocal cord palsy, dysphagia, aspiration tendency, tongue deviation, and truncal ataxia. Ferguson et al. [6] reported that gait and motor deficit was the most common postoperative complication of fourth ventricle tumor. It affected $56 \%$ of patient and lateral extension of tumor is associated with increased incidence of postoperative gait disturbance. In their series, $38 \%$ of patients had postoperative speech/swallowing deficits. Anterior extension of tumor significantly associated with this deficit, abutting or invading the brainstem In this context, we suggest that the sooner patients get surgical management before tumor extension, the better with least postoperative complication.

Considering prognostic factor of disease is most important 
Table 1. Cases of ependymoma in the elderly patients ( $\geq 60$ years old) from the literature

\begin{tabular}{lclcccc}
\hline \multicolumn{1}{c}{ Study } & Age/sex & \multicolumn{1}{c}{ Location } & WHO grade & Presentation & Treatment & Result \\
\hline Saito et al. [10] & 63/F & Lt parietal lobe & n.a. & Consciousness disturbance & GTR & Improved \\
Ehtesham et al. [11] & $72 / \mathrm{M}$ & Lt lateral ventricle & III & Memory disturbance & GTR & Improved \\
Sugawara et al. [12] & $71 / \mathrm{M}$ & Cerebellum & III & Dizziness & STR & Died \\
Araki et al. [13] & 67/F & Fourth ventricle & II & Dizziness, vomiting & STR & Improved \\
Lord et al. [14] & 63/M & Fourth ventricle & II & Vomiting, deteriorating mental state & R+RT & Improved \\
Montano et al. [15] & $73 / \mathrm{M}$ & Fourth ventricle & II & Headache, vomiting & GTR & n.a. \\
Scheithauer et al. [16] & $71 / \mathrm{M}$ & Sella turcica & n.a. & HTR+RT & Improved \\
Shintaku et al. [17] & $72 / \mathrm{F}$ & Lt temporal lobe & III & Language disturbance & R+RT & died \\
Hayashi et al. [5] & $71 / \mathrm{F}$ & Fourth ventricle & III & Gait disturbance, memory & STR+ & moderate \\
& & & & disturbance & VP shunt & disabled \\
Present case & $74 / F$ & Fourth ventricle & II & Aysmptomatic & GTR & Improved \\
\hline
\end{tabular}

Adapted from Hayashi et al. Neurol Med Chir (Tokyo) 2012;52:611-6 [5]. GTR, gross total resection; Lt, left; n.a., not available; R, resection (detail was not described); RT, radiotherapy; STR, subtotal resection; WHO, World Health Organization; VP, ventriculo-peritoneal

things to know. Age, sex, preoperative Karnofsky Performance Scale (KPS) score, tumor location, extent of surgery, WHO grade, Ki-67 index, adjuvant rt had great impact on the prognosis of infratentorial ependymoma. In this case, female, KPS $=80$, WHO grade II, Ki-67 index $<10 \%$ (3\%), GTR are good prognostic factor. But 68 year old, lateral and floor extension, no adjuvant RT has bad effect on the prognosis [3].

Also, it is important to consider genetic and molecular alteration like RELA, YAP-1, CIMP. But insurance is not covered these examination in Kore, thus we do not check molecular and genetic alteration. We did not consider adjuvant therapy like radiotherapy, because tumor was gross totally resected on postoperative MRI.

When we reviewed the benign brain tumors in the elderly, most of their treatment plans were wait-and-see. Because, patients diagnosed brain tumor at least 60 years of age presented four times the mortality risk of being between the ages of 18 and 59 [7] and generally elderly benign tumor grow slowly. Although WHO grade is different, meningioma and vestibular schwannoma had revealed the tumor growth rate on wait-andsee follow up period. The mean growth speed of meningioma was $4.94 \mathrm{~cm}^{3} /$ year in volume and $0.37 \mathrm{~cm} /$ year in diameter. Doubling time of it was 8 years [8]. Similarly, vestibular schwannomas also grow slowly. Initial growth rate in extrameatal vestibular schwannomas was $4.90 \mathrm{~mm} /$ year at first year following mean annual growth rate $2.79,1.15$, and $0.75 \mathrm{~mm} /$ year [9]. But these studies did not specific the growth rate in elderly patients. Our case was found in old age (68 year-old) without any symptoms and we observed the growth of the tumor by annual MRI follow-up. The largest tumor diameter increased from $9 \mathrm{~mm}$ to $30 \mathrm{~mm}$ during six years and the apparent annual mean growth rate of diameter was $3.0 \mathrm{~mm} /$ year. Our case is a rare case of continuously growing 4 th ventricle ependymoma in elderly. Considering this case, we suggest that the elderly who diagnosed with 'supposed-to-be-benign' brain tumor need close follow-up to determine the future surgical intervention and to minimize the postoperative complication.

\section{Conflicts of Interest}

The authors have no potential conflicts of interest.

\section{Acknowledgments}

This work was supported by a grant from the National Cancer Center, Korea (NCC-1710871-2), and the Korea Health industry Development Institute of Ministry of Health and Social Welfare, Republic of Korea (H1731340-1).

\section{REFERENCES}

1. Metellus P, Guyotat J, Chinot O, et al. Adult intracranial WHO grade II ependymomas: long-term outcome and prognostic factor analysis in a series of 114 patients. Neuro Oncol 2010;12:976-84.

2. Mork SJ, Loken AC. Ependymoma: a follow-up study of 101 cases. Cancer 1977;40:907-15.

3. Guyotat J, Metellus P, Giorgi R, et al. Infratentorial ependymomas: prognostic factors and outcome analysis in a multi-center retrospective series of 106 adult patients. Acta Neurochir (Wien) 2009;151:947-60.

4. Jung TY, Jung S, Kook H, Baek HJ. Treatment decisions of World Health Organization grade II and III ependymomas in molecular era. J Korean Neurosurg Soc 2018;61:312-8.

5. Hayashi T, Inamasu J, Kanai R, Sasaki H, Shinoda J, Hirose Y. Clinical, histological, and genetic features of fourth ventricle ependymoma in the elderly. Neurol Med Chir (Tokyo) 2012;52:611-6.

6. Ferguson SD, Levine NB, Suki D, et al. The surgical treatment of tumors of the fourth ventricle: a single-institution experience. J Neurosurg 2018;128:339-51.

7. Amirian ES, Armstrong TS, Gilbert MR, Scheurer ME. Predictors of survival among older adults with ependymoma. J Neurooncol 2012; 107:183-9.

8. Jung HW, Yoo H, Paek SH, Choi KS. Long-term outcome and growth rate of subtotally resected petroclival meningiomas: experience with 38 cases. Neurosurgery 2000;46:567-74; discussion 574-5.

9. Stangerup SE, Caye-Thomasen P, Tos M, Thomsen J. The natural history of vestibular schwannoma. Otol Neurotol 2006;27:547-52.

10. Saito T, Oki S, Mikami T, et al. [Supratentorial ectopic ependymoma: a case report]. No Shinkei Geka 1999;27:1139-44.

11. Ehtesham M, Kabos P, Yong WH, Schievink WI, Black KL, Yu JS. Development of an intracranial ependymoma at the site of a pre-existing 
cavernous malformation. Surg Neurol 2003;60:80-2; discussion 83.

12. Sugawara T, Murakami R, Saito R, et al. [Two cases of ependymoma with atypical presentation]. Rinsho Hoshasen 2003;48:1218-21.

13. Araki T, Shimono T, Kuwabara M, et al. [Two cases of ependymoma with atypical presentation]. Rinsho Hoshasen 2008;53:1141-5.

14. Lord H, Ironside J, Summers D, Gregor A, Erridge S, Myles L. Fourth ventricle ependymoma in father and son. Br J Neurosurg 2008;22:423-5.

15. Montano N, De Bonis P, Doglietto F, et al. Teaching NeuroImage: hem- orrhagic ependymoma in the elderly: a rare cause of headache and gait imbalance. Neurology 2008;70:e95.

16. Scheithauer BW, Swearingen B, Whyte ET, Auluck PK, Stemmer-Rachamimov AO. Ependymoma of the sella turcica: a variant of pituicytoma. Hum Pathol 2009;40:435-40.

17. Shintaku M, Hashimoto K. Anaplastic ependymoma simulating glioblastoma in the cerebrum of an adult. Brain Tumor Pathol 2012;29:31-6. 